\title{
Noncontact plating technique in an open fracture
}

This article was published in the following Dove Press journal:

Therapeutics and Clinical Risk Management

8 June 2017

Number of times this article has been viewed

\section{Ümit Tuhanioğlu \\ Hasan Ulaș Oğur \\ Hakan Çiçek \\ Fırat Seyfettinoğlu \\ Osman Çiloğlu \\ Ahmet Kapukaya}

Department of Orthopaedics and Traumatology, Adana Numune Training and Research Hospital, Adana, Turkey
Correspondence: Ümit Tuhanioğlu Department of Orthopaedics and Traumatology, Adana Numune Training and Research Hospital, Sarıçam Mah., Ege Bagatur Blv., 01260 Yüreğir/Adana, Turkey

Tel +90543622 I873

Email umittuhanioglu@gmail.com.tr
Aim: In comparison with closed fractures, open fractures have an increased risk of infection, there are soft tissue-related problems, and difficulties are experienced in union. The aim of this study was to evaluate and discuss the results of osteosynthesis applied with a noncontact plate in Gustilo-Anderson Type 2, 3a, and 3b fractures.

Method: The study included 23 patients applied with debridement + noncontact plate osteosynthesis + soft tissue procedures in a single session for the treatment of an open fracture. A follow-up card was created to evaluate the patients in respect of age, gender, fracture level, fracture etiology, open fracture type, preoperative and postoperative sedimentation and C-reactive protein values, antibiotics used and duration of use, time to union, and complications.

Results: In all 23 patients, full bone union was obtained at mean 22.5 weeks (range: 16-36 weeks). Complications developed in 9 patients. Implant failure occurred in 3 patients. In 5 patients, infection developed which required repeated debridements.

Conclusion: In open fractures, noncontact plating following debridement seems to be a good alternative treatment method to intramedullar nailing, especially in metaphyseal and metaphyseodiaphyseal fractures and in spiral oblique diafiz fractures. Noncontact plating may also be a good alternative to intramedullar nailing for open fracture treatment if the patients have additional pathologies such as contusion and thoracic injury.

Keywords: plating, open fracture, infection

\section{Introduction}

In comparison with closed fractures, open fractures have an increased risk of infection, there are soft tissue-related problems, and difficulties are experienced in union. In this context, open fractures constitute a group of cases for which orthopedic surgical management is difficult and for which the percentage of complications is high. ${ }^{1,2}$ With the addition of soft tissue and union problems, the need for repeated operations in these patients significantly reduces the quality of life, and relatively low clinical scores are obtained at the end of treatment. ${ }^{2}$ The aim of the treatment is to regain the function of the extremity in a short time and to complete this process with the minimum possible complications. Achieving this target in open fractures is possible by first reducing the risk of infection and then applying procedures that will provide a stable fracture fixation and sufficient soft tissue coverage.

In recent years, the application of primary intramedullary nailing (IMN) after debridement in open fractures and approaches that have provided soft tissue coverage has started to be used more often, especially in fracture types that are suitable for fixation with IMN. Although the mechanical superiority of IMN is accepted, in the primary application after open fractures, in addition to very good results, serious complications have also been reported. ${ }^{3}$ The most resistant infections experienced after open fractures have been reported to be secondary in fractures treated with IMN. ${ }^{4}$ 
Radical debridement, in particular, and the use of intravenous antibiotics in the early period have been shown to significantly reduce the risk of infection in open fractures..$^{5-8}$ From this point, following successful clinical results, there has been a gradual move to treatment protocols with all the procedures applied in a single session rather than treatment protocols with a temporary external fixator applied in the first stage and definitive fracture fixation and soft tissue repair left to different sessions. Every fracture does not have suitable indications for IMN, and despite the good results obtained, the combination with highly resistant infections has created a need for a different application that will provide sufficient, stable fixation and reduce the rates of both deep and resistant infections.

The aim of this study was to evaluate and discuss the results of osteosynthesis applied with a noncontact plate in Gustilo-Anderson Type 2, 3a, and 3b fractures.

\section{Materials and methods}

The study included 23 patients who underwent debridement + noncontact plate osteosynthesis + soft tissue procedures in a single session for the treatment of open fracture. The patients comprised 17 males and 6 females with a mean age of 32.9 years (range: $17-54$ years). Patients included in the study were those with Gustilo-Anderson Type 2, 3a, and 3b fractures. Exclusion criteria were Type 1 and $3 c$ fractures and intra-articular fractures. A follow-up card was created to evaluate the patients in respect of age, gender, fracture level, fracture etiology, open fracture type, preoperative and postoperative sedimentation and CRP values, antibiotics used and duration of use, time to union and complications. The fracture etiology was a traffic accident in 11 patients, a gunshot injury in 7, and a fall from height in 5. According to the GustiloAnderson classification, 10 fractures were Type 2, 11 were Type $3 \mathrm{a}$, and 2 were Type $3 \mathrm{~b}$. Fracture locations were the femur in 9 cases and the tibia in 14. In 5 tibia and 6 femur cases, the fracture was multifragmented. Diaphyseal fracture was determined in 7 cases and metaphyseal in 16 (Table 1). Written informed consent was obtained from all the patients before the interventions. This study was approved by the local ethics committee of Adana Numune Training and Research Hospital (ANEAH EK 2016-39).

\section{Surgical technique}

All patients were operated upon under general or spinal anesthesia. With the exception of 3 patients who presented late, all the patients were admitted for surgery within the first 8 hours. A lateral approach was used in femoral fractures and

Table I Patient data

\begin{tabular}{|c|c|c|c|c|c|c|c|c|}
\hline Patient & $\begin{array}{l}\text { Age } \\
\text { (years) }\end{array}$ & Gender & $\begin{array}{l}\text { Gustilo- } \\
\text { Anderson }\end{array}$ & $\begin{array}{l}\text { Fracture } \\
\text { localization }\end{array}$ & Complications & $\begin{array}{l}\text { Time to } \\
\text { union (weeks) }\end{array}$ & $\begin{array}{l}\text { Additional } \\
\text { operation }\end{array}$ & $\begin{array}{l}\text { Production } \\
\text { in culture }\end{array}$ \\
\hline $\mathrm{I}$ & 24 & $M$ & Type 2 & Femur distal & None & 18 & - & - \\
\hline 2 & 33 & M & Type 3A & Tibia proximal & Infection & 16 & Debridement & MRSA \\
\hline 3 & 32 & $M$ & Type 2 & Tibia shaft & Infection & 17 & Debridement & MRSA \\
\hline 4 & 34 & $\mathrm{~F}$ & Type 3A & Femur shaft & Implant failure & 27 & Revision & - \\
\hline 5 & 43 & $M$ & Type 2 & Tibia shaft & None & 16 & - & - \\
\hline 6 & 54 & $M$ & Type 3A & Tibia proximal & None & 18 & - & - \\
\hline 7 & 44 & $\mathrm{~F}$ & Type 3A & Femur distal & $\begin{array}{l}\text { Infection and skin } \\
\text { necrosis }\end{array}$ & 19 & Debridement & MRSA \\
\hline 8 & 35 & M & Type 3B & Tibia proximal & None & 33 & - & - \\
\hline 9 & 37 & $\mathrm{~F}$ & Type 3A & Femur distal & None & 34 & - & - \\
\hline 10 & 24 & $M$ & Type 2 & Tibia distal & None & 20 & - & - \\
\hline II & 52 & $M$ & Type 3A & Tibia proximal & Infection & 36 & Debridement & Pseudomonas \\
\hline 12 & 25 & $\mathrm{~F}$ & Type 3A & Femur distal & None & 23 & - & - \\
\hline 13 & 28 & $M$ & Type 2 & Tibia distal & None & 19 & - & - \\
\hline 14 & 17 & $M$ & Type 2 & Femur shaft & None & 22 & - & - \\
\hline 15 & 36 & $M$ & Type 3A & Femur distal & Infection & 26 & Debridement & Enterococcus \\
\hline 16 & 41 & $\mathrm{~F}$ & Type 2 & Tibia proximal & None & 17 & - & - \\
\hline 17 & 23 & $M$ & Type 2 & Tibia shaft & None & 20 & - & - \\
\hline 18 & 18 & $\mathrm{~F}$ & Type 3B & Tibia distal & Implant failure & 36 & Revision & - \\
\hline 19 & 44 & $M$ & Type 2 & Femur shaft & None & 17 & - & - \\
\hline 20 & 24 & $M$ & Type 3A & Femur distal & None & 18 & - & - \\
\hline 21 & 36 & $M$ & Type 3A & Tibia shaft & None & 22 & - & - \\
\hline 22 & 22 & $M$ & Type 3A & Tibia distal & Implant failure & 25 & Revision & \\
\hline 23 & 32 & $M$ & Type 2 & Tibia distal & Infection & 20 & Debridement & MRSA \\
\hline
\end{tabular}

Abbreviations: MRSA, methicillin-resistant Staphylococcus aureus; F, female; M, male. 
a distal anteromedial or proximal anterolateral approach in tibial fractures. First, in all patients, extensive debridement was applied, including necrotic tissues and avascular bone fragments. Irrigation was then made with $5 \mathrm{~L}$ of saline and $5 \mathrm{~L}$ of rifocin solution. Before and after irrigation, deep culture was taken from all patients. Fixation was applied according to minimally invasive osteosynthesis principles with a locking plate appropriate to the fracture pattern. Application of noncontact plate was achieved by providing a plate-bone distance of 3-5 mm with an osteotome placed between the plate and the bone. All patients were checked with fluoroscopy. According to the status of the soft tissue coverage of the defect, primary closure was applied in 16 cases, split thickness skin graft in 5 cases, and soleus muscle flap in 2 cases. Postoperatively, no plaster cast or brace was applied to any patient. Daily follow-up was applied to the wound site.

Patients with Type 2 open fractures were administered cefazolin for 2 weeks, and patients with Type 3 fractures were administered a combination of cefazolin for 2 weeks and aminoglycoside for 5 days. As a result of the cultures taken, patients with production determined were administered antibiotherapy of appropriate dose and duration defined by the Infectious Diseases department according to the agent. On Postoperative Day 1, patients were mobilized with a walker and joint movements were started (Figure 1A-F). Under the supervision of a physiotherapist, passive and active range of motion exercises were explained to the patients, and follow-up was done at specified intervals. Postoperative follow-up examinations were performed on the 15 th
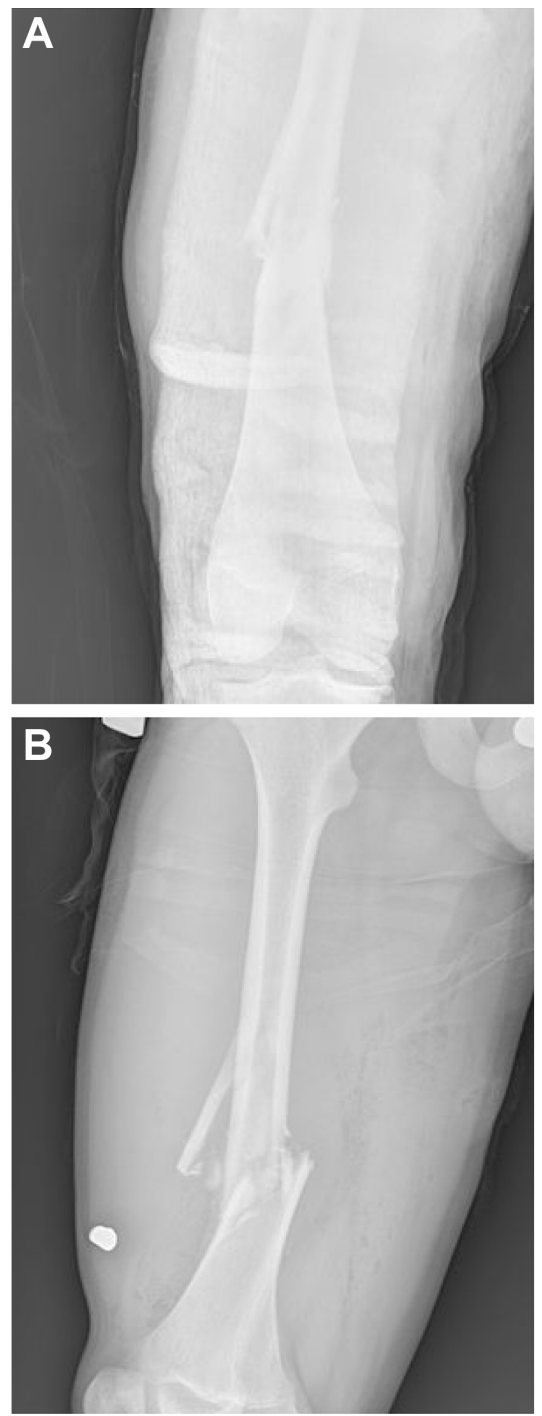
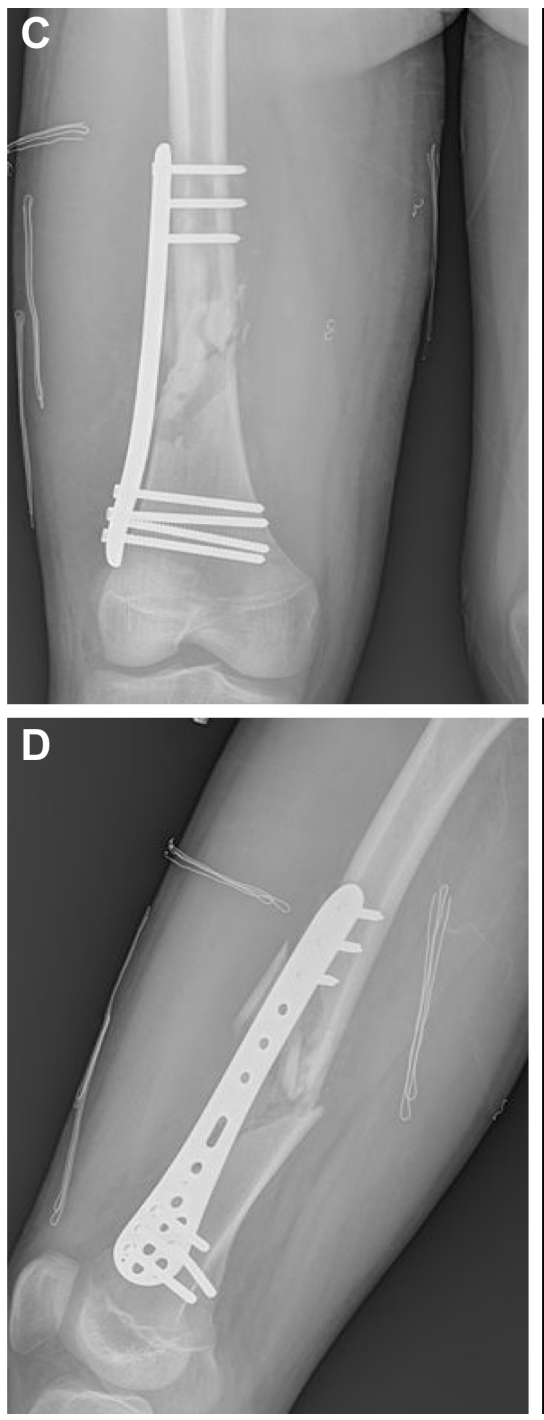

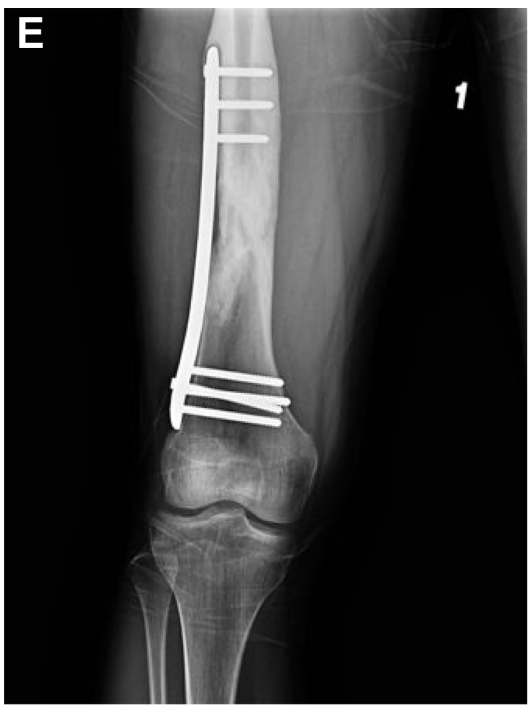

$\mathbf{F}$

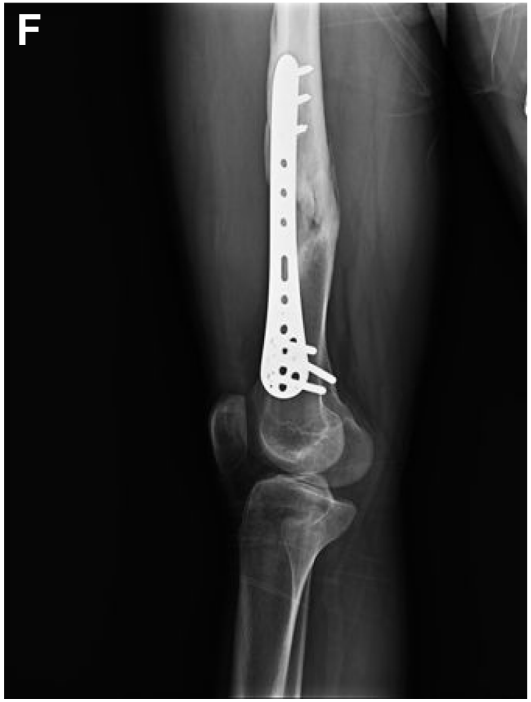

Figure I A 17-year-old male patient with Type 2 open femur fracture due to traffic accident.

Notes: (A, B) Preoperative anteroposterior (AP) and lateral radiographs. (C, D) AP and lateral radiographs following noncontact plating. (E, F) AP and lateral radiographs at 6-month follow-up showed adequate union. 
and 45 th days, then at 3 months, 6 months, and 1 year with routine direct radiographs, sedimentation, CRP, and full blood count.

\section{Statistical analysis}

The data used in the study were not suitable for testing statistical hypothesis due to unattainable randomization of the sample and certain problems in conducting a designed representative control experiment. However, the study assesses the performance of "noncontact plating technique" via descriptive statistics, and certain quantities for those are given in the Results section.

\section{Results}

In all the 23 patients, full bone union was obtained at mean 22.5 weeks (range: 16-36 weeks). Clinical and radiographic full union was obtained at mean 18.6 weeks in the patients with Type 2 open fractures, at mean 24 weeks in Type $3 \mathrm{a}$ patients, and at mean 34.5 weeks in Type $3 \mathrm{~b}$ patients. Complications developed in 9 patients. Implant failure occurred in 3 patients who underwent revision with refixation and autograft taken from the iliac wing. Union was obtained in these 3 patients at mean 17 weeks after the revision surgery. In 6 patients, infection developed that required debridements. Although 1 further debridement was sufficient for recovery in 3 patients, despite union after 3 debridements in 2 patients, chronic osteomyelitis developed. Wound site necrosis developed in 1 patient, and recovery was obtained after debridement and split thickness grafting. In 3 patients, foot dorsiflexion restriction was determined, and in 4 patients, knee flexion restriction of $<20^{\circ}$. These restrictions were observed not to limit the daily activities of the patients (Table 2). When the time to union was compared in respect of different fracture etiologies, the results were found to be close. In 5 of the 11 patients with a fracture etiology of traffic accident, in 2 of the 5 with etiology of fall from height, and in 2 of the 5 with firearms injuries, a secondary intervention was necessary.

\section{Discussion}

Open fractures are prone to complications such as nonunion and the development of infection due to both the soft tissue and bone damage caused by the severity of the trauma and as a result of the injured area being contaminated by the outside environment. ${ }^{9}$ From the past to the current day, external fixators have been an important component of the staged treatment of open fractures. However, external fixators cannot provide sufficient stability biomechanically and create a risk of pin site infection in addition to the open fracture.
Table 2 Type of fracture and cause

\begin{tabular}{|c|c|c|c|c|}
\hline Case & $\begin{array}{l}\text { Mechanism } \\
\text { of injury }\end{array}$ & OTA & $\begin{array}{l}\text { Gustilo- } \\
\text { Anderson }\end{array}$ & $\begin{array}{l}\text { Fracture } \\
\text { localization }\end{array}$ \\
\hline $\mathrm{I}$ & Traffic accident & OTA A & Type 2 & Femur distal \\
\hline 2 & Fall from height & OTA B & Type 3A & Tibia proximal \\
\hline 3 & Traffic accident & OTA A & Type 2 & Tibia shaft \\
\hline 4 & Traffic accident & OTA C & Type 3A & Femur shaft \\
\hline 5 & Traffic accident & OTA C & Type 2 & Tibia shaft \\
\hline 6 & Gunshot injury & OTA B & Type 3A & Tibia proximal \\
\hline 7 & Gunshot injury & OTA A & Type 3A & Femur distal \\
\hline 8 & Fall from height & OTA B & Type 3B & Tibia proximal \\
\hline 9 & Gunshot injury & OTA C & Type 3A & Femur distal \\
\hline 10 & Fall from height & OTA A & Type 2 & Tibia distal \\
\hline 11 & Fall from height & OTA B & Type 3A & Tibia proximal \\
\hline 12 & Traffic accident & OTA C & Type 2 & Femur distal \\
\hline 13 & Gunshot injury & OTA A & Type 3A & Tibia distal \\
\hline 14 & Gunshot injury & OTA B & Type 3A & Femur shaft \\
\hline 15 & Traffic accident & OTA B & Type 3A & Femur distal \\
\hline 16 & Traffic accident & OTA C & Type 2 & Tibia proximal \\
\hline 17 & Traffic accident & OTA C & Type 2 & Tibia shaft \\
\hline 18 & Traffic accident & OTA A & Type 3B & Tibia distal \\
\hline 19 & Gunshot injury & OTA B & Type 3A & Femur shaft \\
\hline 20 & Fall from height & OTA C & Type 2 & Femur distal \\
\hline 21 & Traffic accident & OTA B & Type 2 & Tibia shaft \\
\hline 22 & Gunshot injury & OTA A & Type 3A & Tibia distal \\
\hline 23 & Traffic accident & OTA C & Type 2 & Tibia distal \\
\hline
\end{tabular}

Abbreviation: OTA, Orthopaedic Trauma Association.

Another negative feature of external fixators is the low level of patient tolerance. ${ }^{10}$ In recent years, in particular, a trend has been observed to move away from multistage surgery to single-stage surgery for these fractures.

In reports in the literature that have compared two-stage treatment of open fractures using external fixators with cases applied with primary definitive treatment, no significant difference has been found in respect of the development of infection. ${ }^{11}$ Despite its disadvantages including low patient tolerance, pin site infection, and insufficient fracture stability, external fixator application is still used by many surgeons for open fractures. ${ }^{12}$ Both unilateral and circular external fixators remain a primary treatment option for defective and highly contaminated open fractures. ${ }^{13,14}$

The primary application of IMN as the basis in open fractures has been used at increasing rates in recent years. The basic principle in this application is radical debridement and antibiotic prophylaxis to minimize the risk of contamination. In a meta-analysis that compared two patient groups of open tibial fractures treated with fixation with primary IMN after radical debridement and IMN after external fixator, it was reported that the times to union, nonunion, and malunion rates were lower in the group applied with primary IMN. ${ }^{15}$ In an extensive series treated with IMN, it was emphasized that deep infections developed and that union problems were secondary to periosteal injury and the application of external fixators. ${ }^{16,17}$ 
In open fractures with soft tissue and periosteal injury, the iatrogenic impairment of medullary canal circulation in reamerized nailing and the development of cortical necrosis are related to deep infection. Pin site infections created by external fixators and the negative effect of reamerized nailing on medullary circulation have brought unreamed nailing to the fore in the treatment of open fractures. ${ }^{18}$ Although unreamed intramedullary nails provide an advantage in respect of the risk of infection, it is not a fixation method that can be used as an alternative to plate application in terms of stability in fractures extending to the joint or in metaphyseal fractures. In addition, it is not possible to apply nails without reaming of a thickness that will provide sufficient fixation in diaphyseal fractures.

Although many studies have used staged definitive treatment with IMN, very few have used the noncontact plate, as in this study. ${ }^{19,20}$ With the application of the noncontact plate, biomechanical stability was provided for all the patients of this study to a degree close to that of the conventional plate, without iatrogenic impairment of the fracture circulation and offering the possibility of application to diaphyseal, metaphyseal, and intra-articular fractures. Union was obtained in all the 23 patients at mean 22.5 weeks. Implant failure developed in 3 patients, deep infection in 5 , and wound site necrosis in 1 , similar to the findings in the literature. The 5 patients in whom deep infection developed recovered with repeated debridement and agent-specific intravenous antibiotic treatment without the need for implant removal, and union was obtained in all cases. This suggests that the noncontact plate is more resistant to the creation of a biofilm layer and is more effective than conventional plating in the intervention against infection. ${ }^{16}$ This feature is comparable to other studies in respect of both union and infection. ${ }^{3,4,20}$

It has been shown that soft tissue coverage occurring in the early stage has positive effects both on the development of secondary infection and on fracture healing. ${ }^{21-23}$ In this study, soft tissue coverage was provided in all patients following debridement and fixation. When the technique was compared with external fixation, biological noncontact plating provided closure both in cases with split thickness grafting and in those with soleus muscle flap. As in this study, positive results have been previously reported in the sense of both fracture union and obtaining a high functional result by providing soft tissue coverage and a biomechanically stable fixation, and in terms of postoperative care and rehabilitation for patients. ${ }^{23,24}$

In interventions against the development of infection in open fractures, the importance of stable fixation of the fracture has been emphasized. ${ }^{25}$ One aspect of the noncontact plating applied in this study was the provision of stability and fixation close to that of conventional plating. ${ }^{26,27}$ Another aspect was that it contributed to the appropriate dose of antibiotics reaching the tissues and the nourishment of the tissues by preserving the periosteal circulation and the soft tissue connection to the fracture. ${ }^{16-20}$

The agent initially isolated from the wound has been found to be the agent in only $18 \%$ of infections developing secondary to open fractures. ${ }^{28}$ In the other $82 \%$ of cases, an agent different from the initial agent has been isolated. This is probably due to contamination from the external environment in cases where there has been late closure of the wound in secondary interventions or because of pin site infections created by the external fixator. In this sense, it can be assumed, in contrast to the traditionally accepted views, that primary debridement, primary definitive fixation, and wound closure would relatively reduce the risk of infection.

The timing of the first intervention and debridement in open fractures is very important. It has been observed that treatment within the first 8 hours, in particular, significantly reduces the risk of complications and infection. ${ }^{16}$ Of the 5 cases of infection that developed in the current series, the first intervention in 3 of these cases was made after mean 12 hours, and the development of deep infection in these 3 cases supports these previous findings.

In open fractures, contact between the bone and the implant, in particular, is known to play a primary role in the development of infection and biofilm. ${ }^{13-16}$ With the application of a noncontact plate, there is no contact between the bone and the implant, and the connection between the two is only with screws. Appropriately placed screws in the biological plating technique are further from the fracture line compared to those in conventional plating. This can be considered to make the formation of infection and biofilm more difficult. In addition, as the lever arm is short compared to that of external fixators, a more stable fixation is provided. ${ }^{18}$ Thus, noncontact plating can be considered an alternative method for single-stage treatment of open fractures.

\section{Conclusion}

In open fractures, noncontact plating following debridement seems to be a good alternative treatment method to intramedullar nailing, especially in metaphyseal and metaphyseo-diaphyseal fractures and in spiral oblique diafiz fractures. Noncontact plating may also be a good alternative to intramedullar nailing for open fracture treatment if the patients have additional pathologies such as contusion and thoracic injury. In addition, as there is no damage to 
the intramedullary circulation and periosteal circulation as secondary injuries of open fractures, it can also be considered a treatment alternative for diaphyseal femur and tibia fractures to avoid implant failure that could be created by unreamed nailing.

A limitation of this study can be said to be the low number of cases. Furthermore, a study that is made within group comparisons of different types according to the open fracture classification would reach more objective results.

\section{Disclosure}

The authors report no conflicts of interest in this work.

\section{References}

1. Court-Brown CM, Bugler KE, Clement ND, Duckworth AD, McQueen MM. The epidemiology of open fractures in adults. A 15-year review. Injury. 2012;43(6):891-897.

2. Khatod M, Botte MJ, Hoyt DB, Meyer RS, Smith JM, Akeson WH. Outcomes in open tibia fractures: relationship between delay in treatment and infection. J Trauma. 2003;55(5):949-954.

3. Cordero-Ampuero J. The management of open fractures of the tibial diaphysis. Eur Instr Course Lect. 2007;8:42-48.

4. Berkes M, Obremskey WT, Scannell B, Ellington JK, Hymes RA, Bosse M. Southeast Fracture Consortium. Maintenance of hardware after early postoperative infection following fracture internal fixation. J Bone Joint Surg Am. 2010;92:823-828.

5. Hoff WS, Bonadies JA, Cachecho R, Dorlac WC. East Practice Management Guidelines Work Group: update to practice management guidelines for prophylactic antibiotic use in openfractures. J Trauma. 2011; 70(3):751-754.

6. Okike K, Bhattacharyya T. Trends in the management of open fractures. A critical analysis. J Bone Joint Surg Am. 2006;88(12):2739-2748.

7. Gosselin RA, Roberts I, Gillespie WJ. Antibiotics for preventing infection in open limb fractures. Cochrane Database Syst Rev. 2004;(1):CD003764.

8. Al-Arabi YB, Nader M, Hamidian-Jahromi AR, Woods DA. The effect of the timing of antibiotics and surgical treatment on infection rates in open long-bone fractures: a 9-year prospective study from a district general hospital. Injury. 2007;38(8):900-905.

9. Rajasekaran S, Naresh Babu J, Dheenadhayalan J, et al. A score for predicting salvageand outcome in Gustilo type-IIIA and type-IIIB open tibial fractures. J Bone Jt Surg Br. 2006;88:1351-1360.

10. Papakostidis C, Kanakaris NK, Pretel J, Faour O, Morell DJ, Giannoudis PV. Prevalence of complications of open tibial shaft fractures stratified as per the Gustilo-Anderson classification. Injury. 2011;42: 1408-1415.

11. Harwood PJ, Giannoudis PV, Probst C, Krettek C, Pape HC. The risk of local infective complications after damage control procedures for femoral shaft fracture. J Orthop Trauma. 2006;20(3):181-189.

12. Tornetta P, Bergman M, Watnik N, Berkowitz G, Steuer J. Treatment of grade-IIIb open tibial fractures. A prospective randomised comparison of external fixation and non-reamed locked nailing. $J$ Bone Joint Surg Br. 1994;76:13-19.

Therapeutics and Clinical Risk Management

\section{Publish your work in this journal}

Therapeutics and Clinical Risk Management is an international, peerreviewed journal of clinical therapeutics and risk management, focusing on concise rapid reporting of clinical studies in all therapeutic areas, outcomes, safety, and programs for the effective, safe, and sustained use of medicines. This journal is indexed on PubMed Central, CAS,
13. Schlegel U, Perren SM. Surgical aspects of infection involving osteosynthesis implants: implant design and resistance to local infection. Injury. 2006;37(2):S67-S73.

14. Oosterbos CJ, Vogely HC, Nijhof MW, et al. Osseointegration of hydroxyapatite-coated and noncoated Ti6Al4V implants in the presence of local infection: a comparative histomorphometrical study in rabbits. J Biomed Mater Res. 2002;60:339-347.

15. Xu X, Li X, Liu L, Wu W. A meta-analysis of external fixator versus intramedullary nails for open tibial fracture fixation. J Orthop Surg Res. 2014;9:75.

16. Hofmann A, Dietz SO, Pairon P, Rommens PM. The role of intramedullary nailing in treatment of open fractures. Eur J Trauma Emerg Surg. 2015;41:39-47.

17. Metsemakers WJ, Handojo K, Reynders P, Sermon A, Vanderschot P, Nijs S. Individual risk factors for deep infection and compromised fracture healing after intramedullary nailing of tibial shaft fractures: a single centre experience of 480 patients. Injury. 2015;46(4):740.

18. Wiss DA, Stetson WB. Unstable fractures of the tibia treated with a reamed intramedullary interlocking nail. Clin Orthop Relat Res. 1995; 315:56-63.

19. Yildırım A, Kapukaya A, Atic R, et al. The use of an "internal fixator technique" to stabilize pathologic fractures developing secondary to osteomyelitis. J Pediatr Orthop. 2017;37(3):222-226.

20. Alemdar C, Azboy I, Atiç R, Özkul E, Gem M, Kapukaya A. Management of infectious fractures with "Non-Contact Plate" (NCP) method. Acta Orthop Belg. 2015;81:523-529.

21. Vaienti L, Di Matteo A, Gazzola R, Pierannunzii L, Palitta G, Marchesi A. First results with the immediate reconstructive strategy for internal hardware exposure in non-united fractures of the distal third of the leg: case series and literature review. J Orthop Surg Res. 2012;7:30.

22. Zalavras CG. Prevention of infection in open fractures. Infect Dis Clin North Am. Epub 2017 Mar 11.

23. Gopal S, Majumder S, Batchelor AG, Knight SL, De Boer P, Smith RM. Fix and flap: the radical orthopaedic and plastic treatment of severe open fractures of the tibia. J Bone Joint Surg Br. 2000;82:959-966.

24. Trlica J, Koc i J, Lochman P, et al. Reamed versus unreamed nail in the treatment of tibia shaft fractures. Eur J Trauma Emerg Surg. 2013;40: 489-493.

25. Zhang F, Zhu Y, Li W, Chen W, Tian Y, Zhang Y. Unreamed intramedullary nailing is a better alternative than external fixator for Gustilo grade IIIB tibial fractures based on a meta-analysis. Scand J Surg. 2016; 105(2):117-124.

26. Sirkin M, Sanders R, DiPasquale T, Herscovici D. A staged protocol for soft tissue management in the treatment of complex pilon fractures. J Orthop Trauma. 1999;13:78-84.

27. Uhl JM, Seguin B, Kapatkin AS, Schulz KS, Garcia TC, Stover SM. Mechanical comparison of $3.5 \mathrm{~mm}$ broad dynamic compression plate, broad limited-contact dynamic compression plate, and narrow locking compression plate systems using interfragmentary gap models. Vet Surg. 2008;37(7):663-673.

28. Patzakis MJ, Bains RS, Lee J, et al. Prospective, randomized, doubleblind study comparing single-agent antibiotic therapy, ciprofloxacin, to combination antibiotic therapy in open fracture wounds. $J$ Orthop Trauma. 2000;14:529-533.

EMBase, Scopus and the Elsevier Bibliographic databases. The manuscript management system is completely online and includes a very quick and fair peer-review system, which is all easy to use. Visit $\mathrm{http}: / /$ www.dovepress.com/testimonials.php to read real quotes from published authors. 